\title{
Big step of regional science in Latin America
}

\author{
Patricio Aroca ${ }^{1}$
}

Published online: 25 February 2017

(C) The Japan Section of the Regional Science Association International 2017

The Japan Section of the Regional Science Association International (JSRSAI) has played a key role in promoting the development of regional science in Latin America through the Pacific Regional Science Conference Organisation (PRSCO), where two leaders are worthy of mention: first professor Hirotada Kohno and later professor Yoshiro Higano. Using the PRSCO Summer Institutes, they started in 1994 supporting the realization in Mexico. In 2004, they pushed Chilean researchers for organizing the Summer Institute. Later, in 2010 and 2014, they did the same in Colombia and Ecuador, respectively. In all those countries, those meetings were the starting point of their regional science national association of the RSAI.

Nowadays, those countries, together with Argentina and Brazil, have started the Latin American and Caribbean Regional Science Association (LACRSA), a supraregion of the RSAI. This new supra-region owed a great part of its creation to the PRSCO and the leaders of the Japan Section.

The Japan Section had its own journal for 45 years, published in Japanese. Now, in a new effort to promoting regional science around the world and especially around the Pacific Rim, it has decided to publish a sequel of the journal in English, the Asia-Pacific Journal of Regional Science.

In this new effort, I want to first thank the JSRSAI for their commitment to regional science and with the countries in the Pacific Rim. This will be another big step in helping to develop regional science, especially in the Latin American side of the Pacific Rim.

Secondly, I want to congratulate and thank the leaders of the JSRSAI and professor Yoshiro Higano for taking the responsibility to lead the project, in a time where there are several journals struggling to increase their submissions and

Patricio Aroca

patricio.aroca@uai.cl

1 Universidad Adolfo Ibáñez, Viña del Mar, Chile 
citations. Therefore, it will be a hard task to expose the Asia-Pacific Journal of Regional Science in the light that it deserves, due to its history of 45 years.

Finally, I send from Chile my wishes of a successful journey with the expectation that we will have, in the near future, a top journal in regional science published in English and focusing on the Pacific Rim. 